\title{
Complete intraventricular migration of the ventriculoperitoneal shunt
}

\author{
Elif Basaran Gundogdu, Ufuk Ozsoy, Yusuf Tuzun \\ Department of Neurosurgery, University of Health Sciences, Bursa Yuksek Ihtisas Training and Research Hospital, Bursa, Turkey
}

\begin{abstract}
Intracranial migration of the ventriculoperitoneal shunt is an extremely rare situation. A 2-month-old infant who had undergone ventriculoperitoneal shunt for hydrocephalus in the neonatal period presented with feeding problems and increasing head circumference. There was intracranial migration on cranial computed tomography and shunt survey images. Endoscopically the shunt was removed and a new shunt was applied. The patient was discharged with cure. This extremely rare shunt complication and its surgery both have serious complications. Therefore, the surgical technique, proper fixation of the shunt and the use of the right shunting material are significantly important.
\end{abstract}

Eur Res $J$ 2017;3(1):87-89

Keywords: Shunt complication, intraventricular migration, endoscopic procedures

\section{Introduction}

The frequency of intracranial migration of the ventriculoperitoneal shunt is reported to be $0.1-0.4 \%$ in the literature [1]. Direction of the migration is determined by the pressure gradient between the cranial and the peritoneal cavities. The case being reported is an example for the intracranial migration of the ventriculoperitoneal shunt which is extremely rare.

\section{Case Presentation}

A 2-month-old infant who had undergone ventriculoperitoneal shunt for hydrocephalus in the neonatal period presented with feeding difficulty and increasing head circumference. She was hospitalized. The shunt catheter was not palpable on the cranium, the cervical region or the anterior chest wall. On cranial computed tomography (CT), the shunt was completely in the ventricle and acute hydrocephalus was seen. Also the parenchyma was extremely thinned. On shunt survey images, there was no continuity of the shunt catheter, so an external ventricular drain (EVD) catheter was introduced immediately and a clear cerebrospinal fluid (CSF) leak was observed (Figure $1 \mathrm{a}, \mathrm{b}, \mathrm{c}$ ). The patient was reoperated since there was no bacterial growth in the CSF culture and there was no fever. The EVD catheter 

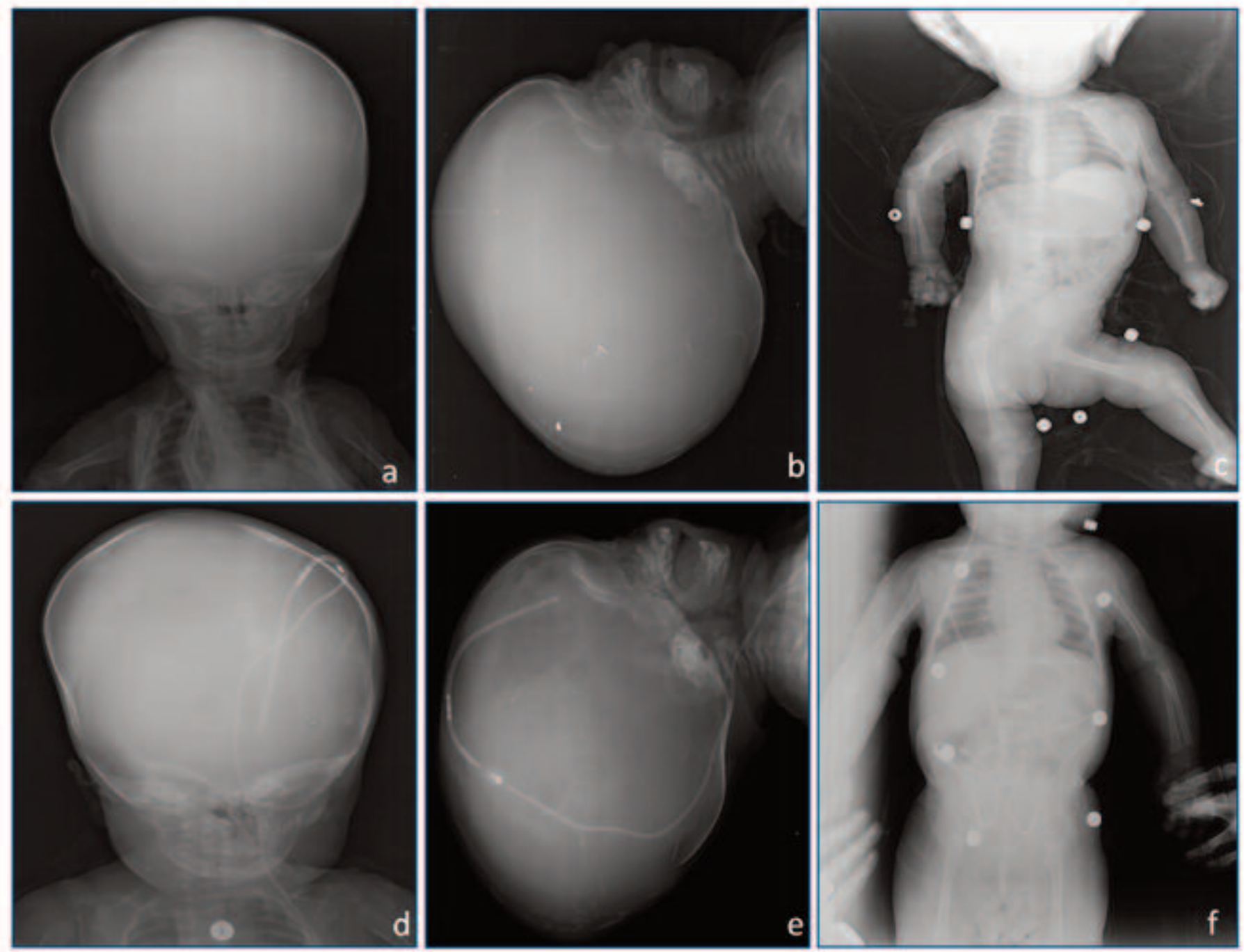

Figure1. Preoperative (a, b, c) and postoperative (d, e, f) x-rays images of ventriculoperitoneal shunt.

was removed, and the new shunt catheter was inserted endoscopically. After inserting the new shunt catheter, the old catheter was removed from the right frontal region (Figure $1 \mathrm{~d}, \mathrm{e}, \mathrm{f}$ ). The patient was discharged with cure.

\section{Discussion}

Complications of the ventriculoperitoneal shunt are frequently reported for patients with hydrocephalus in the literature. Although migration of the distal edge of the ventriculoperitoneal shunt is common, intracranial migration is a rare complication and it has been reported in $0.1-0.4 \%$ of the cases [1]. Despite continuously developing shunting technology, $33 \%$ of the patients who had undergone shunt experience dysfunction of the shunt at the end of the first year, $50 \%$ after 2 years and $70 \%$ after 10 years [2].

In migration of cranial edge of the shunt, lower pressure and mechanical factor providing continuation of the shunt catheter within cranium have been considered as responsible [3, 4]. In other words, if the cranial pressure is high, the catheter will move towards the abdomen, and if the abdominal pressure is high, the catheter will move towards the cranium [3, 5]. As Ceran-Rous et al. [6] have reported, underlying diseases (porencephaly), dynamic causes such as abdominal peristaltic movements, dynamic translocation factors such as cervical movements, dynamic attraction factors such as increased CSF reabsorption may cause migration of the shunt. Flexion and extension movements of the neck in childhood can play a role in upward migration of the shunt catheter. In children, since the distance between the ventricular and the peritoneal edges of the catheter is shorter than that in adults, proximal migration more readily occurs. Having seizures and constipation play roles in proximal migration of the shunt catheter [4, 7]. Yilmaz et al. [8] suggested that, detachment of the shunt from its attachment sites due to development of 
the child, as well as abdominal peristaltic movements, cervical flexion and extension movements, and the history of seizures might be responsible for migration of the ventricular catheter.

The second most common cause of shunt migration in pediatric patients is interruption and detachment of the shunt. Predisposing factors are shunt design, the material used and the surgical technique. Any fixation point can cause interruption by causing tension of the shunt. In addition, immune reaction can cause calcification and dissolution of the shunt material $[9,10]$. During surgical procedure, a loose binding or use of absorbable suture material on connection part can lead to detachment in the shunt system by causing tension. Metal instruments can cause small erosions or even full-thickness tears leading to detachments. Risk for shunt detachment occurs only if a connection part is present in the shunt system. For one-piece shunts there is no such problem $[11,12]$. Within shunt material, a catheter whose distal tube is stuck with valve and other wall is coated with pure silicone (to prevent calcification) is the best choice when ventricular edges are bound appropriately [13].

When complete intraventricular shunt migration was searched in the PubMed, 10 cases were encountered. Although this situation is extremely uncommon, both the case itself and the surgical procedure are quite risky. In cases in which the shunt is migrated towards the ventricle; anemia, sepsis and hydrocephalus cause cortical atrophy [14]. Situations such as presence of adhesions to the choroid plexus can lead to intraventricular hemorrhage while the shunt is being extracted [15]. To prevent this, avoiding burr holes and wide dural incisions, and attention to proper fixation of the shunt are critical $[16,17]$.

\section{Conclusion}

Complete intraventricular shunt migration is an extremely rare case. The situation itself and its surgery both have extremely severe complications. To prevent this, the surgical technique, proper fixation of the shunt and the use of the right shunting material are significantly important.

\section{Informed consent}

Written informed consent and photography release forms were obtained from the parents of the patient for the publication of this case report.

\section{Conflict of interest}

The authors declared that there are no potential conflicts of interest with respect to the research, authorship, and/or publication of this article.

\section{References}

[1] Acharya R, Bhutani A, Saxena H, Madan VS. Complete migration of ventriculoperitoneal shunt into the ventricle. Neurol Sci 2002;23:75-7.

[2] Ammirati M, Raimondi A. Cerebrospinal fluid shunt infections in children. A study of the relationship between the etiology of the hydrocephalus, age at the time of shunt placement, and infection rate. Childs Nerv Syst 1987;3:106-9.

[3] Choudhury AR. Avoidable factors that contribute to the complications of ventricüloperitoneal shunt in childhood hydrocephalus. Childs Nerv Syst 1990;6:346-9.

[4] Shimizu S, Machizuki T, Nakayama K, Fujii K. Visual field defects due to a shunt valve migration into the cranium. Acta Neurochir (Wien) 2002;144:1055-6.

[5] Serlo W, Fernell E, Heikkinen E, Anderson H, Von Wendt L. Functions and complications of shunt in different etiologies of childhood hydrocephalus. Childs Nerv Syst 1990;6:92-4.

[6] Cerron-Rojas VR, Vega-Basulto S, Varela-Hernandez A, Montejo-Montejo J, Gutierrez-Munoz FG. [Simultaneous cephalic migration of a ventriculoperitoneal shunt into the intraventricular and subdural spaces. A case report]. Rev Neurol 2001;33:437-9. [Article in Spanish]

[7] Kanai M, Kawano K, Uehara S. Upward migration of the L-P shunt catheter in to the cranial base. Osaka City Med J 1999;45:1237.

[8] Yilmaz N, Kiymaz N, Yilmaz C, Yazici T, Bay A. [The intracranial milgration of ventricular catheter of ventriculoperitoneal shunt]. Van Tip Dergisi 2005;12:164-6. [Article in Turkish]

[9] Echizenya K, Satoh M, Mural H, Ueno H, Abe H, Komai T. Mineralization and biodegradation of CSF shunting systems. Neurosurg 1987;67:584-91.

[10] Sugar O, Bailey OT. Subcutaneous reaction to silicone in ventriculoperitoneal shunts. Long-term results. J Neurosurg 1974;41:367-71.

[11] Haase J, Bang F, Tange M. Danish experience with the onepiece shunt. A long-term follow-up. Childs Nerv Syst 1987;3:93-6.

[12] Raimondi AJ, Robinson JS, Kuwawura K. Complications of ventriculoperitoneal shunting and a critical comparison of the threepiece and one-piece systems. Child's Brain 1977;3:321-42.

[13] Karatas MA, Dagtekin A, Avci E, Bagdatoglu C. [Shunt disfunctions]. Turk Norosirurji Dergisi 2013;2:202-7. [Article in Turkish]

[14] Oluwole KE, Abiodun AA. Complete intraventricular migration of a ventriculo-peritoneal shunt. A case report and brief literature review. Afr J Neurol Sci 2007;26:69-74.

[15] Sharma RK, Bansal M, Agrawal M, Gupta A, Sinha VD. Complete intracranial migration of a ventriculoperitoneal shunt: rare complication of a common procedure. Neurol India 2015;63;106-7. [16] Naik V, Phalak M, Chandra PS. Total intracranial shunt migration. J Neurosci Rural Pract 2013;4:95-6.

[17] Sengul G, Tuzun Y, Kadioglu HH, Aydin IH. Complete intraventricular unisystem ventriculoperitoneal shunt migration. Pediatr Neurosurg 2005;41:337-8. 